\title{
A propósito de um texto de Habermas: a herança brasileira de um dilema da civilização ocidental
}

\author{
EDUARDOR. CRUZ
}

Sentimos que, mesmo que todas as questões científicas possíveis tenham obtido resposta, nossos problemas de vida não terão sido sequer tocados. Wittgenstein, Tractatus, 6.52.

\section{Introdução}

$\mathrm{O}$ S ACONTECIMENTOS de 11 de setembro de 2001 trouxeram novamente à baila as relações entre estado secular, religiões institucionalizadas e o potencial criativo e destrutivo do sentimento religioso. Muitos analistas, dentro e fora dos círculos religiosos, apressaram-se em afirmar que haveria dois tipos de religião: a "autêntica", representada pela maioria dos fiéis, que se contentam em ser um grupo tolerante dentro de um Estado secular, obedecendo-lhe as regras; e a "distorcida", teocrática, totalitária, identificando estruturas religiosas com estruturas estatais, como por exemplo o conjunto de leis a serem obedecidas por todos os cidadãos.

Muitas soluções têm sido assim apontadas para essa "ameaça aos valores ocidentais", todas na linha de submeter as diversas religiões à tutela de um Estado livremente constituído pelos cidadãos, exercendo a tolerância mútua e a função de suprir as necessidades espirituais de seus fiéis.

Ainda no mesmo ano, o filósofo alemão Jürgen Habermas pronunciou uma palestra sobre o tema, logo traduzida e difundida por todo o mundo, tendo recebido recentemente uma tradução oficial no Brasil ${ }^{1}$. Resumindo argumentos e temas caros ao Iluminismo e ao Liberalismo clássico, ele introduz, entretanto, uma nuance que é mais raramente encontrada. Trata-se de apontar para a possibilidade de um diálogo mutuamente fértil entre fé e saber, no contexto da valoração de atitudes propriamente humanas. Vamos explorar um pouco melhor seu argumento, para que tenhamos critérios de análise para a "relação fé-ciência" no ocidente e no Brasil.

\section{Habermas e o papel da religião em um mundo pós-secular}

Para Habermas, os acontecimentos de 11 de setembro tocaram "uma corda religiosa no âmago da sociedade secular" levando a um incremento do sentimento e da prática religiosos em escala mundial. Uma reação religiosa a outra reação do mesmo tipo: aquela dos tradicionalistas em face do avanço inexorável 
da secularização. Mesmo na Europa a secularização ainda gera sentimentos ambivalentes ${ }^{2}$. Aqui o autor antecipa sua tese: "Quem quiser evitar uma guerra entre as civilizações precisa se lembrar da dialética inacabada do nosso próprio processo ocidental de secularização" (p. 137). A consciência do fracasso desse processo, segundo ele, leva então a uma sociedade pós-secular. Enquanto a secular lida com a religião por processos de substituição e apropriação de conteúdos religiosos, a pós-secular admite a persistência do religioso e a coexistência pacífica das esferas de sentido. Enquanto o Estado secular emascula a religião e só a admite sem quaisquer pretensões cognitivas, o pós-secular tem certa sensibilidade em relação ao poder e ao conhecimento do religioso. Também admite uma certa neutralidade em relação às pretensões de autoridade tanto das ciências, quanto das religiões. Podemos dizer que Habermas é um pouco ambíguo em relação a este ponto $^{3}$, mas sua atenção se dirige mais à comunidade política e ao senso comum (algo compartilhado por esta comunidade, influenciado tanto pela ciência como pelas idéias religiosas), que na modernidade se tem esclarecido pela ciência.

Frente às tentativas contemporâneas de naturalizar a intencionalidade e a moral (temática analisada na primeira parte do livro), Habermas defende a autonomia da esfera política relativamente à descrição científica, assim como esta esfera tem-se emancipado da tutelagem da religião (pp. 140-145). Mas a recíproca também é verdadeira: não só a ciência proclama sua autonomia em relação a ingerências políticas, como também a religião protesta contra o avanço do secular na esfera pública: "O Estado liberal, por sua vez, desperta nos fiéis a suspeita de que a secularização ocidental poderia ser uma via de mão única, que deixaria a religião à margem" (p. 145). O Estado secular trabalha, assim, com dois pesos e duas medidas: ao respeitar a autonomia da ciência, fá-lo de modo a colocá-la no centro da esfera pública; ao não interferir no religioso, acaba deixando-o à margem da esfera das decisões político-sociais.

Habermas parece ter plena consciência da sombra que Kant projeta neste debate. Por um lado, Kant celebra a separação entre a esfera do privado (à qual pertenceria a religião institucional) e a esfera pública (à qual pertencem o Estado e a ciência). Por outro, indica que existe a possibilidade de uma tradução eficiente, que transforme valores de uma religião específica em valores públicos, comuns a todos. Esta possibilidade é respaldada pela própria experiência histórica do ocidente, que pode reconhecer as raízes religiosas das instituições modernas. É a tese da continuidade do religioso e do secular, defendida por alguns (Löwith) e combatida por outros (Blumenberg).

É nessa tradução que a "dialética inacabada" referida acima encontra sua expressão maior. Muitos modernos sustentam que seus valores surgiram em oposição aos valores religiosos assim como transmitidos pelas respectivas instituições, enquanto talvez uma sociedade pós-secular seja chamada a ter uma sensibilidade maior em relação ao poder de articulação das linguagens religiosas (p. 
146). Como seus predecessores na Escola de Frankfurt, Habermas identifica na Teodicéia o ponto onde essa tradução se processa (e continuará se processando) de forma inacabada. A passagem da noção de pecado para a de mal deixa um resíduo religioso (ou um reservatum religiosum) tal que, diante do mal radical, o secular se abre ao religioso (pp. 148-149). Por conta do mal, Hegel falará da "Vitória de Pirro da razão" iluminista (p. 150), e surgirá no século XX o "anelo do inteiramente outro" (Horkheimer): "Ela [razão] sabe que Deus não existe, mas continua a acreditar nele" (pp. 150-151).

Resignação, pieguismo, realismo, sobriedade? Conclui Habermas: "Nesse sentido, a razão profana, mas não derrotista, mantém, por sua parte e com um grande respeito, a brasa sempre suscetível de se tornar chama, quando se coloca a questão da teodicéia para se aproximar da religião" (p. 15l, grifo do autor). Mas será só a teodicéia a chave para tornar a "via de mão única" da secularização em outra de mão dupla? A partir de uma temática diferente, mas não de todo, vamos argumentar que não.

\section{A religião expulsa do Éden cognitivo, e seu retorno}

Podemos já nos desvencilhar da herança existencialista de meados de século XX, e pensar em termos mais positivos a "via de mão dupla" sugerida por Habermas. Ainda na esteira de Kant, que destaca o aspecto moral da religião, várias alianças felizes têm-se registrado entre o secular e o religioso no campo da ética social. Mas quando se passa ao plano pessoal, enormes diferenças (como no caso da ética de reprodução) indicam a "dialética inacabada" entre as duas esferas. $\mathrm{O}$ mesmo Kant, outrossim, abre o caminho para um interdito, o de manter doutrinas teológicas no âmbito do saber público.

De fato, fica claro que Habermas, ao pensar o título de seu ensaio como "Fé e saber", equaciona "fé” com religião e "saber" com ciência. Essa associação, quase automática na modernidade, segue inquestionada em círculos acadêmicos e midiáticos. Mesmo um físico simpático à religião como Marcelo Gleiser (vide seu $A$ dança do universo) recentemente afirmou o seguinte:

Antes de serem estudas pelos cientistas, eram [as questões mais antigas da humanidade] "respondidas" pela religião. As aspas são para lembrar que as respostas religiosas nem sempre estão de acordo, pelo contrário. É só haver as chacinas entre muçulmanos e hindus na Índia e Paquistão ou as Cruzadas (as medievais e a atual), para constatar que a revelação pela fé é uma escolha subjetiva ${ }^{4}$.

Dois aspectos salientam-se nessa afirmação. Primeiro, a idéia de que a religião teve uma função cognitiva, agora suplantada pela ciência. Depois, parte da razão disto seria a incongruência entre as respostas religiosas, com implicações no plano moral. A solução: relegar a fé para o plano subjetivo. Porém, o próprio Gleiser, ao destacar o caráter platônico da cosmologia contemporânea, fala do Uno, do Deus geômetra que rege o universo. Por mais metafórica que tenha 
sido essa alusão, ainda sim ela dá margem a especulações teológicas que permitem o diálogo entre as religiões, e destas com as ciências.

Podemos citar ainda uma outra matéria que afirma um senso comum sobre a temática de "Fé e saber". Trata-se de uma recente resenha de vários livros, pelo repórter Reinaldo J. Lopes 5 . Ao comentar um deles, na linha de "E a Bíblia tinha razão", ele constata que "apesar da boa vontade de membros das comunidades científica e religiosa, o fato é que os abismos entre fé e ciência ainda são uma das questões mais complexas a afligir ambos os lados. O diálogo é necessário e até possível [...]" (p. 16, col. b). Sobre o caminho a ser seguido, ele parece dar razão a Stephen J. Gould, que reiterava em seus últimos escritos (em particular no resenhado por Reinaldo Lopes, Pilares do tempo) a relevância do princípio do Noma (Non-overlapping magisteria, traduzido como MNI "magistérios não interferentes"), entendido da seguinte forma:

Ciência e religião precisam uma da outra, argumenta ele [Gould]: ambas são pilares de impulsos humanos fundamentais, o de entender os fatos do Universo e o de estabelecer propósitos, finalidades, certos e errados, respectivamente. Os dois lados têm de controlar sua tendência a invadir o domínio do vizinho, mas só podem se enriquecer com o diálogo e a compreensão mútua (p. 17 , col. a)

Certamente é um avanço em relação a uma simples substituição de um pilar pelo outro, ao modo positivista, mas será que tal solução de coexistência pacífica é factível, de modo a produzir um diálogo mutuamente fértil? Será que o contínuo esforço de colocar a ciência ao lado do conhecimento e a religião ao lado dos propósitos não dificultaria este diálogo?

Creio que um outro ponto de partida seja necessário para entender o que está acontecendo, e para propor possíveis caminhos a partir daí. A premissa básica é valorizar-se o caráter cognitivo da religião ${ }^{6}$. A razoabilidade desta premissa vai sendo afirmada ao longo do argumento que se segue.

Como corolário desta premissa, sustentamos que no lado da ciência também há questões de princípios e finalidades (vide o caso da cosmologia, já citado acima, ou os intermináveis debates sobre finalidade e progresso em biologia evolutiva, ou ainda a tensão entre o "é" e o "deve ser" para uma ética baseada na ciência [Drees, 2003 e Daston e Vidal, 2004]), assim como no lado da religião as pretensões cognitivas não podem ser eliminadas (Slone, 2004).

Um importante passo neste sentido tem sido dado por recentes avanços nas ciências cognitivas, dentro do paradigma darwiniano. No plano da psicologia evolutiva, mesmo que se trabalhe com uma perspectiva modular da mente, não se costuma falar de um "módulo científico" ou um "módulo religioso" (Atran, 2002). Em planos que atravessam a arqueologia, a antropologia e as ciências cognitivas, a base comum da produção da religião e da ciência é destacada, tanto para os "primitivos" como para os modernos (Atran, 1990 e 2002; 
Barnes, 2000 e Mithen, 1996). Esses estudos, por preliminares que sejam, têm em comum o seguinte: primeiro, deixam de lado o padrão religião-como-moral para analisar seu aspecto cognitivo; enfocam não apenas a "função social ou psicológica" da religião, como nos clássicos das ciências sociais, mas também as idéias religiosas: as crenças a respeito do início e do fim, de deuses, de demônios e do mundo sobrenatural.

Só estas últimas figuras já bastariam para acender a luz vermelha de muitos modernos. Gerações de eminentes cientistas têm se dedicado a mostrar a possibilidade de se manter a religião, mas demitologizada e reinterpretada pela ciência (Broom, 2003), ou a vacuidade das idéias religiosas em face das explicações naturalistas da ciência. O psicólogo inglês Nicholas Humprey tem em seu Leaps of Faith (prefaciado por Daniel Dennett) um capítulo significativamente intitulado “That Hypothesis" (seguido por outro, "Who Needs it?”), fazendo referência à resposta de Laplace à pergunta de Napoleão sobre o lugar de Deus na ciência. Ao longo do livro ele, na linha de Jacques Monod, mostra que a "consolação sobrenatural" não só é irreal e inútil, como também danosa para o progresso do humano. Novamente, isto permitiria um diálogo entre ciência e religião (se o permitir!) apenas no plano moral, em respeito à integridade de alguns líderes religiosos.

Mas “a persistência dos deuses" (Hinde, 1999) nos obriga a continuar, mesmo que em face de tão poderosos argumentos. Se "as origens da arte, da religião e da ciência" (Mithen, 2002) coincidem com a emergência do Homo sapiens sapiens, é difícil asseverar como fato comprovado (barrando o próprio ceticismo científico) que a religião pertenceria apenas à pré-história humana, sendo agora o resíduo de um animismo construído nas nuvens. Isso quer dizer que as ciências "provariam" a existência de deuses e demônios? Certamente que não, como pode sugerir qualquer epistemologia sã que fale dos limites do conhecimento científico. Mas isto tampouco quer dizer que o conhecimento religioso seria delirante!

\section{O retorno dos espíritos impuros}

Podemos agora voltar por mais um momento a Habermas e sua dialética inacabada. A ciência moderna é ambivalente, no sentido de ser vítima de seu próprio sucesso. O astrofísico Carl Sagan assim o sugere, ao mostrar como a ciência se tornou frágil em face de superstições que se arvoram em conhecimento - a maioria ganhando feições modernas com a pretensão mesma de serem “científicas” (Sagan, 1996 e Cruz, 2000)! Há uma resistência inquebrantável de muitos movimentos do intelecto, a maioria com intenções soteriológicas. Antes de pensar sobre a realidade dos demônios, portanto, precisamos reconhecer os “espíritos impuros” que invadem a casa do intelecto assim que esta é limpa por métodos rigorosos, no plano empírico e lógico, no esforço de tornar mais confiável a descrição científica da realidade. 
A esta tendência histórica denominei em um ensaio anterior de "Efeito Mateus II", fazendo referência tanto ao "efeito Mateus" de Robert K. Merton como ao trecho do evangelho de Mateus 12,43-45, em que Jesus fala dos espíritos impuros que invadem a casa pela porta dos fundos, assim que ela é limpa (Cruz, 1995). Habermas sustenta de maneira explícita que o fundamentalismo é um fenômeno basicamente moderno. É preciso lembrar (ele não o faz) que o fundamentalismo nasceu como fenômeno intelectual no início do século XX, como reação de grupos protestantes norte-americanos aos excessos da teologia liberal então vigente. Ambos os pólos visavam a expulsar os demônios supostamente cultivados pelo outro. Se a religião fosse matéria puramente privada, talvez isto não passasse de um conflito intestino dentro de um grupo social particular.

Porém, ao cabo de uma história longa e complexa ${ }^{7}$ (que passa pelo romantizado julgamento de Scopes), encontra-se a partir dos anos de 1960 o "criacionismo científico". Este reage contra o establishment darwiniano (lembrar que o ensino da teoria da evolução nas escolas norte-americanas só se disseminou a partir dos anos de 1950), apresentando fragmentos do discurso e do trabalho científicos e dos filósofos da ciência, com o fito de se apresentarem como ciência sólida a respeito das origens da terra e do homem.

Execrado pela maioria dos cientistas, é também apresentado como uma interferência da Religião na esfera pública da ciência. Recentemente tive oportunidade de sugerir (seguindo as análises de vários autores norte-americanos) que se trata, não de um confronto entre fé e ciência, mas sim daquele entre boa e má religião de um lado, e de boa e má ciência de outro (Cruz, 2004). É claro que a divisão moderna entre "boa" e "má" religião foi questionada acima, dada a ambivalência desta última, similar à da ciência. Porém, isto não exclui um julgamento de valor adequado às circunstâncias. $\mathrm{O}$ fato da boa e da má religião, por assim dizer, requererem-se mutuamente, não justifica o costume de enfrentar o "lado escuro" da religião esvaziando-a de seu conteúdo cognitivo.

Neste mesmo artigo, tive oportunidade de desenvolver uma rápida análise sobre o criacionismo no Brasil. Com o aumento expressivo do número de evangélicos (vide censo de 2000), aumentam também em número os criacionistas. Ainda que nem todos grupos evangélicos sejam criacionistas, a influência de tendências fundamentalistas norte-americanas é muito forte. Até o momento, essas idéias desenvolvem-se mormente em escolas dominicais (pesquisas de campo ainda precisam ser feitas a respeito), mas a migração delas para a esfera pública é quase que inexorável. O caso recente do Estado do Rio de Janeiro é um indicativo dessa tendência, expressando um resultado concreto da expansão da influência evangélica na política. Adicione-se a isto que cresce o número de profissionais universitários e pesquisadores de adesão evangélica, e teremos que o criacionismo (e seu sucedâneo mais sofisticado, a "teoria do plano inteligente") pode sim ganhar espaço na academia. Mas aqui também faltam estudos empíricos a respeito. De qualquer forma, é preciso se preparar para essa eventualidade. 
Como sugere o número da revista Comciência de julho de 2004, a reação preponderante do establishment científico brasileiro é semelhante à norte-americana: sem separar o joio do trigo, muitos destinam o todo da religião à esfera moral e privada. Mas a "resistência inquebrantável" daqueles que se sentem excluídos do conhecimento oficial pode ser também encontrada aqui ${ }^{8}$. Mal ou bem, o Brasil também pertence ao Novo Mundo, tornando-se herdeiro do patrimônio da modernidade Européia. Também aqui a secularização se faz presente, a despeito de toda nossa diversidade e efervescência religiosa (Pierucci, 2004), e com ela, todas as vicissitudes de sua história.

É por isso que a análise da "dialética inacabada" da modernidade que Habermas faz é relevante para o nosso contexto. Trata-se de reconhecer a natureza das forças que supostamente impedem o "progresso da ciência" e a racionalidade moderna em nosso país. Trata-se, outrossim, de reconhecer os parceiros nesta dialética, que possam auxiliar a comunidade científica a enfrentar criativamente estas forças. Caso se passe a admitir as pretensões cognitivas de segmentos religiosos expressivos no Brasil, "os abismos entre a fé e a ciência" podem efetivamente ser superados: pode-se perceber que há mais similaridades do que diferenças, e que o conjunto destas será útil no combate a inimigos comuns. Assim como a "guerra de civilizações" é uma noção questionável, também o é a "guerra ciência - religião": como vimos acima, sendo comum a origem natural de ambas, pode-se entender a "guerra" como algo contingente. $\mathrm{O}$ lado demoníaco desta natureza é que está em questão.

\section{Conclusão}

De fato, não é adequado se comparar "religião" e "ciência”. Seria um erro de categoria. Mais apropriado seria comparar a teologia (cristã, judaica ou islâmica) com a ciência. Mas os teólogos, desde o início de nossa era, insistem que os dados da fé não podem ser "provados" pelo conhecimento profano, o que pareceria reforçar a idéia de que a religião é matéria de foro íntimo.

Podemos afirmar que a teologia e a ciência se encontram sim no plano filosófico, e a epígrafe de Wittgenstein acima parece sugerir isto. Mas há uma ressalva: em muitas das citações desta tese do filósofo, omite-se a última parte dela: "e é claro então que não sobra questão alguma, e justamente isto é a resposta". Proposições como essa levaram os membros do círculo de Viena a julgar questões metafísicas como sem sentido, e este julgamento é ainda muito comum na comunidade científica. Porém, também a metafísica entra "pela porta de trás" se a expulsamos publicamente. As alusões ao Deus dos cosmólogos, à finalidade biológica e à moralidade da natureza acima sugerem sua atualidade, indicam a razoabilidade do encontro no plano da metafísica e da ética?

Quaisquer que sejam as posições de princípio, encaminhamentos práticos nos últimos anos têm resultado em pesquisa interdisciplinar com cientistas, teólogos, filósofos e historiadores da ciência ${ }^{10}$. Ainda que concordemos com Ha- 
bermas que a "dialética inacabada" da secularização assombre-nos ainda mais depois de 2001, e que dilemas existenciais abram a razão à religião, o fato é que isto ainda não localiza positivamente a religião (ou a teologia) na esfera da razão pública. Nosso argumento aqui tem enfatizado a valorização, no Brasil, de um trabalho sério de pesquisa e ensino em torno do tema "ciência e religião". Este trabalho não se sustenta apenas na boa vontade e competência dos indivíduos envolvidos, mas em percepções básicas acerca da natureza humana e da realidade do mundo exterior. Esta também é a base para se minimizar a alienação de cientistas e elites religiosas de parcelas expressivas da população e seus problemas. $\mathrm{O}$ mesmo trabalho pode viabilizar um ensino religioso relevante em escolas privadas ou públicas, mas isto é matéria para deliberações posteriores.

\section{Notas}

l Jürgen Habermas, "Fé e saber", em O futuro da natureza humana: a caminho de uma engenia liberal? São Paulo, Martins Fontes, 2004, pp. 135-154. As numerações de páginas a seguir referem-se a esta edição.

$2 \mathrm{O}$ autor escreve antes do debate recente, e da conseqüente legislação, em torno do uso de símbolos religiosos em escolas públicas francesas. Talvez a França seja um caso destacado desta ambivalência.

3 Parece-nos que o Estado está longe de ser neutro (o que é afirmado por Habermas em outros de seus escritos), e inevitavelmente serve a quem lhe legitima o poder: a Igreja, em um regime de Cristandade; o aparato científico-tecnológico, na sociedade contemporânea.

4 Marcelo Gleiser, "Sonhos de uma teoria final", Folha de S. Paulo, 26/2/2004, Caderno Mais!, p. 18.

5 Reinaldo José Lopes, "Uso e abuso da ciência". Folha de S. Paulo, 28/9/2004, caderno Sinapse, pp. 16-17.

6 Para um bom estudo de síntese do campo denominado "filosofia da religião", ver Trigg, 1998.

7 Não há como retraçar esta história aqui. Para uma história do Criacionismo, e temas correlatos, ver Ferngren, 2002.

$8 \mathrm{O}$ crescimento de formas de religiosidade esotérica entre nós (com pretensões de conhecimento) parece sugerir isto.

9 No caso da física, o papel da metafísica é discutido por exemplo em Redhead, 1995. No caso da biologia, ver Ghiselin, 1997.

10 Para uma importante contribuição, traduzida para o português, ver Peters e Bennett, 2003 
Bibliografia

ATRAN, Scott. Cognitive Foundations of Natural History. Cambridge, Cambridge University Press, 1990.

In Gods we Trust: The Evolutionary Landscape of Religion. Oxford, Oxford University Press, 2002.

BARNES, Michael H. Stages of Thought: The Co-evolution of Religious Thought and Science. Oxford, Oxford University Press, 2000.

BROOM, Donald M. The Evolution of Morality and Religion. Cambridge, Cambridge University Press, 2003.

CRUZ, Eduardo R. "Matthew Effect, Part II". Ciência e Cultura, vol. 47, maio-jun. 1995, pp. 167-173.

"Ciência e milenarismo ao final do século XX: Os demônios de Carl Sagan". Anais do VII Seminário Nacional de História da Ciência e da Tecnologia. São Paulo, Imprensa Oficial/ Edusp/ Ed. Unesp, 2000, pp. 149-157.

"Criacionismo, lá e cá". Com Ciência: Revista Eletrônica de Jornalismo Científico n. 56, jul. 2004. http://www.comciencia.br, acessado em 15/7/2004.

DASTON, Lorraine, e VIDAL, Fernando (eds.). The Moral Authority of Nature. Chicago, The University of Chicago Press, 2004.

DREES, Willem B. (ed.). Is Nature ever Evil? Religion, science and value. London, Routledge, 2003.

FERNGREN, Gary B. (ed.). Science and Religion: A Historical Introduction. Baltimore, Johns Hopkins Press, 2002.

GHISELIN, Michael T. Metaphysics and the origin of species. Albany, New York, SUNY Press, 1997.

GLEISER, Marcelo. "Sonhos de uma teoria final”, Folha de S. Paulo, Caderno Mais!, 26/2/2004, p. 18.

HINDE, Robert A. Why Gods Persist: A Scientific Approach to Religion. London, Reoutledge, 1999.

HUMPHREY, Nicholas. Leaps of Faith: Science, Miracles, and the Search for Supernatural Consolation. Paperback. New York, Copernicus, 1999.

LOPES, Reinaldo José. "Uso e abuso da ciência". Folha de S. Paulo, 28/9/2004, Caderno Sinapse, pp. 16-17.

MITHEN, Steven. A pré-história da mente: uma busca das origens da arte, da religião e da ciência. São Paulo, Ed. Unesp, 2002.

PETERS, Ted, e BENNETT, Gaymon (orgs.). Construindo pontes entre a ciência e a religião. São Paulo, Loyola/ Ed. Unesp, 2003.

PIERUCCI, Antonio F. “Secularização e declínio do Catolicismo”. Em SOUZA, Beatriz M. e MARTINO, Luís M. S. (orgs.). Sociologia da religião e mudança social: católicos, protestantes e novos movimentos religiosos no Brasil. São Paulo, Paulus, 2004, pp. 1321. 
REDHEAD, Michael. Da Física à Metafísica. Campinas, Papirus, 1995.

SLONE, D. Jason. Theological Incorrectness: Why religious People Believe what they Shouldn't. Oxford, Oxford University Press, 2004.

TRIGG, Roger. Racionalidade e religião: precisará a fé da razão? Lisboa, Instituto Piaget, 1998.

RESUMO - HABERMAS, em um texto recente sobre os acontecimentos de 2001, colocou novamente em questão as relações entre fé e saber na modernidade. A visão moderna que a religião deve ser excluída da esfera pública encontra resistências, que sugerem um outro cenário para um mundo pós-secular. Habermas fala do diálogo entre os dois "pilares do tempo" (Gould) apenas para o plano moral, mas o argumento do presente trabalho destaca as razões para se valorizar o aspecto cognitivo da religião. Estudos recentes, principalmente no âmbito das ciências cognitivas, revelam a origem natural comum da ciência e da religião. No âmbito da história e da filosofia, sugerem-se hoje outros elementos comuns para a "fé" e o "saber". No caso brasileiro, enfatiza-se a necessidade de um esforço comum em face de ameaças como o criacionismo, e em prol de uma educação que desenvolva a cidadania e o conhecimento são.

ABSTRACT - HABERMAS, in a recent paper on 9/11, questions again the relationship between faith and knowledge in modernity. The modern outlook, excluding religion in the public realm, faces resistance that suggests another scenario for a post-secular world. He speaks about the dialogue between the two "rocks of ages" (Gould) only at the moral level, but the argument of the present paper highlights the reasons to give more weight to the cognitive role of religion. Recent studies, mainly in the realm of cognitive sciences, reveal the natural origin both of science and religion. In the realm of history and philosophy, other elements are suggested today for "faith" and "knowledge". In the Brazilian case, we emphasize the need for a common effort in face of threats such as creationism, and in favor of educational patterns that foster citizenship and sound knowledge.

Eduardo R. Cruz é professor da Pontifícia Universidade Católica de São Paulo (PUCSP), ligado à área de ciências da religião, com doutorado na Universidade de Chicago (1987). Com formação tanto em física quanto em ciências da religião, tem publicado extensivamente sobre sua área de pesquisa, a interface entre ciência e religião na modernidade.

Texto recebido e aceito para publicação em 4 de outubro de 2004. 